\title{
An Ankle Sprain or Calcaneal Ewing Sarcoma? A case report of a 9 year old boy
}

\author{
Luis Salazar ${ }^{1}$, Abdullah Ghali ${ }^{*}$, David Momtaz ${ }^{1}$, Jacob Malmquist ${ }^{1}$, Saad Masud ${ }^{2}$, Gautham Prabhakar ${ }^{1}$, Anil Dutta $^{1}$ \\ ${ }^{1}$ Long School of Medicine San Antonio Texas.
}

${ }^{2}$ Wayne State school of medicine, Detroit, Michigan

*Corresponding Author: Abdullah Ghali, Long School of Medicine San Antonio Texas.

Received date: January 20, 2021; Accepted date: February 15, 2021; Published date: March 03, 2021

Citation: L Salazar, A Ghali, D Momtaz, J Malmquist, G Prabhakar et al. (2021) An Ankle Sprain or Calcaneal Ewing Sarcoma? A case report of a 9 year old boy. Biomedical Research and Clinical Reviews. 3(3); DOI: 10.31579/2692-9406/044

Copyright: (C) 2021 Abdullah Ghali, This is an open-access article distributed under the terms of the Creative Commons Attribution License, which permits unrestricted use, distribution, and reproduction in any medium, provided the original author and source are credited.

Abstract:
Ewing Sarcoma of the calcaneus is a very rare presentation of the tumor. In this case report, we
present a 9 year old Hispanic male who presented with a limp in the right ankle, thought to be
secondary to a football injury. We also discuss treatment options and various presentations of the
tumor.
Keywords: ankle; leg; malignant tumors; 9-year-old boy

\section{Introduction}

Malignant tumors of the bone in the foot and ankle are an extreme rarity [1]. Though Ewing's sarcoma [ES] is the second most common primary malignant bone tumor in children, its manifestation in feet is rare [1,2]. In general, the tumor has a very low predilection for dissemination to regional lymph nodes, and it is not known to metastasize to adjacent bones 2]. In the Dahlin and Unni publication covering 8,542 tumors of the bone, less than $1.2 \%$ were in the distal extremities [2]. Still, less than a fifth of these tumors were ES. The frequency of ES is less than 1 for every 3 million per year, and of these, an exceedingly small number are found in the foot or ankle [4].

Due to the disease's rare nature and its uncommon presentation in the lower extremities, the diagnosis has proven elusive, and care has not been standardized [1, 3]. Current best practices include chemotherapy with various synergetic drugs that seek to control the local and systemic manifestations of the tumor. Surgery and radiotherapy are also often used for local control of ES [2]. Unfortunately, cases that are not diagnosed quickly have a poor prognosis and receive wide resections or amputations, which comes at the cost of significant loss of function [2]

We present the case of a 9-year-old Hispanic male patient with a nonmetastatic Ewing sarcoma of the ankle with a history of ankle sprains. He presented to the clinic with right ankle pain due to sporting activities. The patient was eventually examined and found to have Ewing sarcoma of the right foot with large lytic lesions in the calcaneus. This paper highlights Ewing Sarcoma's unique presentation as ankle pain and a suspected sprain. To the authors' knowledge, ankle sprains are a highly uncommon presentation of Ewing Sarcoma, and by discussing the case's unique presentation, we hope to bring awareness to various ES presentations that may aid diagnosis. We further discuss the management strategy, course of healing, and the considerations that must be taken in all stages of care, from diagnosis to management of a patient with ES.

\section{Case presentation}

A 9-year-old Hispanic male presented to the clinic with a limp and pain in the right ankle. Initially, the parents disregarded the pain due to an ankle sprain secondary to a football injury. Before seeking medical aid, the patient's family had attempted to treat the pain with ice and local analgesics. Despite these efforts, the pain in the ankle persisted and escalated in severity. The patient was brought to the emergency department when the ankle pain and swelling impacted the patient's gait four months after the football injury.

The patient was evaluated and found to have a suspicious mass in the right calcaneus. Radiographs were ordered and revealed sclerotic and osteolytic changes in the calcaneus and surrounding area [Figure 1-2]. Initial examinations of the patient were unremarkable aside from painful extension and dorsiflexion of the ankle. There was asymmetrically increased uptake in the right calcaneus, right distal talus, and right midfoot. Noncontrast CT images demonstrated central destruction of the right calcaneus with increased sclerosis in the remainder of the bone.

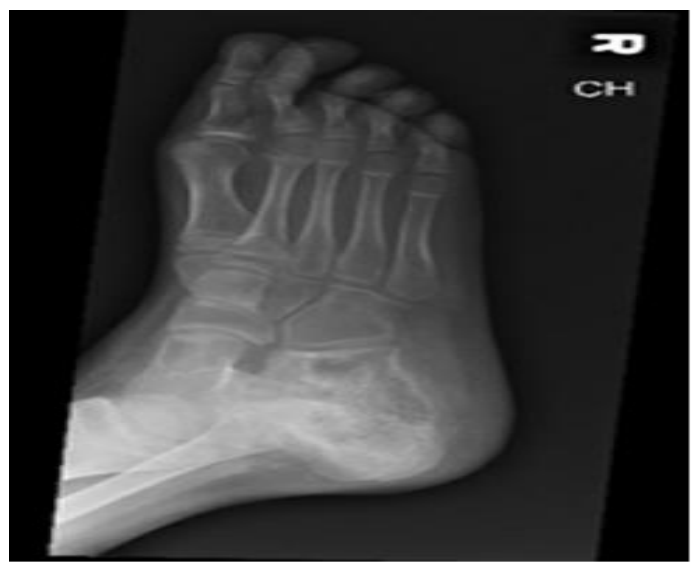

Figure 1: X-ray Oblique internal rotation view 


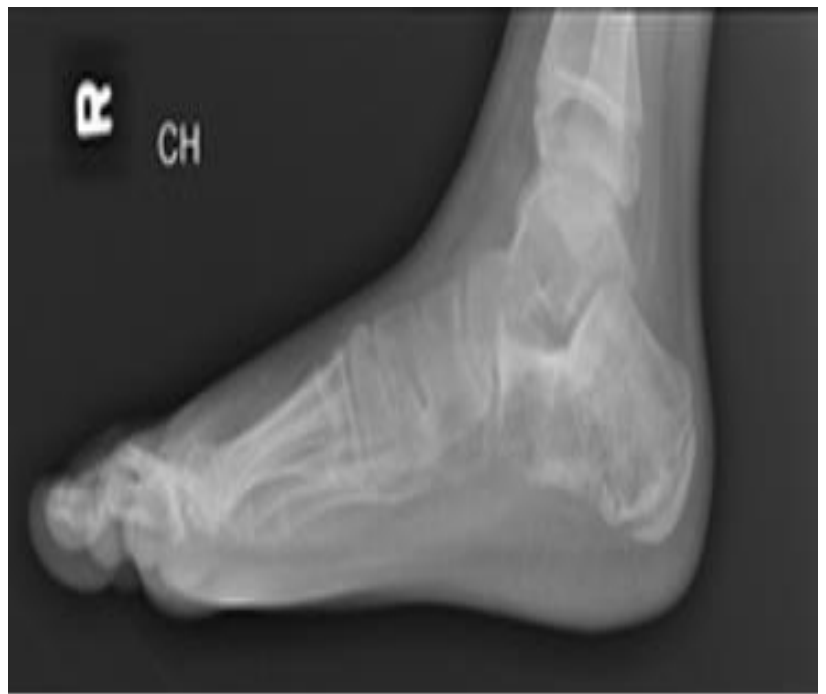

Figure 2: X-ray Lateral view

Flow cytometric immunophenotyping of left posterior iliac crest biopsy was performed and revealed no abnormal lymphoid or blast population. An increased number of maturing hematogenous cells [approximately $10 \%$ of total marrow cells] was noted, and cells were positive for HLADR CD117. The patient was referred to a pediatric oncology with appropriate diagnosis and admission. The patient agreed to neoadjuvant chemotherapy. The patient had a Chest CT and bone scan [Figures 3-5].
Delayed whole body and spot images were obtained. There was focal increased uptake in the right calcaneal region and right mid foot consistent with the patient's history of right calcaneus malignancy. Computer tomography of the chest was normal. The remainder of the patient's skeletal survey showed no evidence of malignancy. No metastasis was noted, and the patient was diagnosed with Ewing Sarcoma. The expansile mass had originated within the calcaneus and expanded posteriorly.

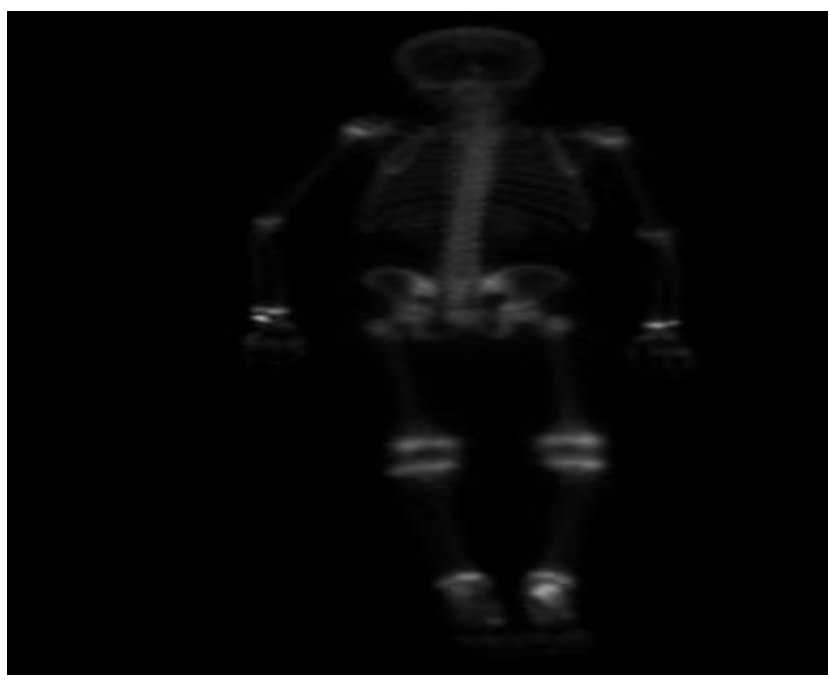

Figure 3: Whole body bone scan with uptake 


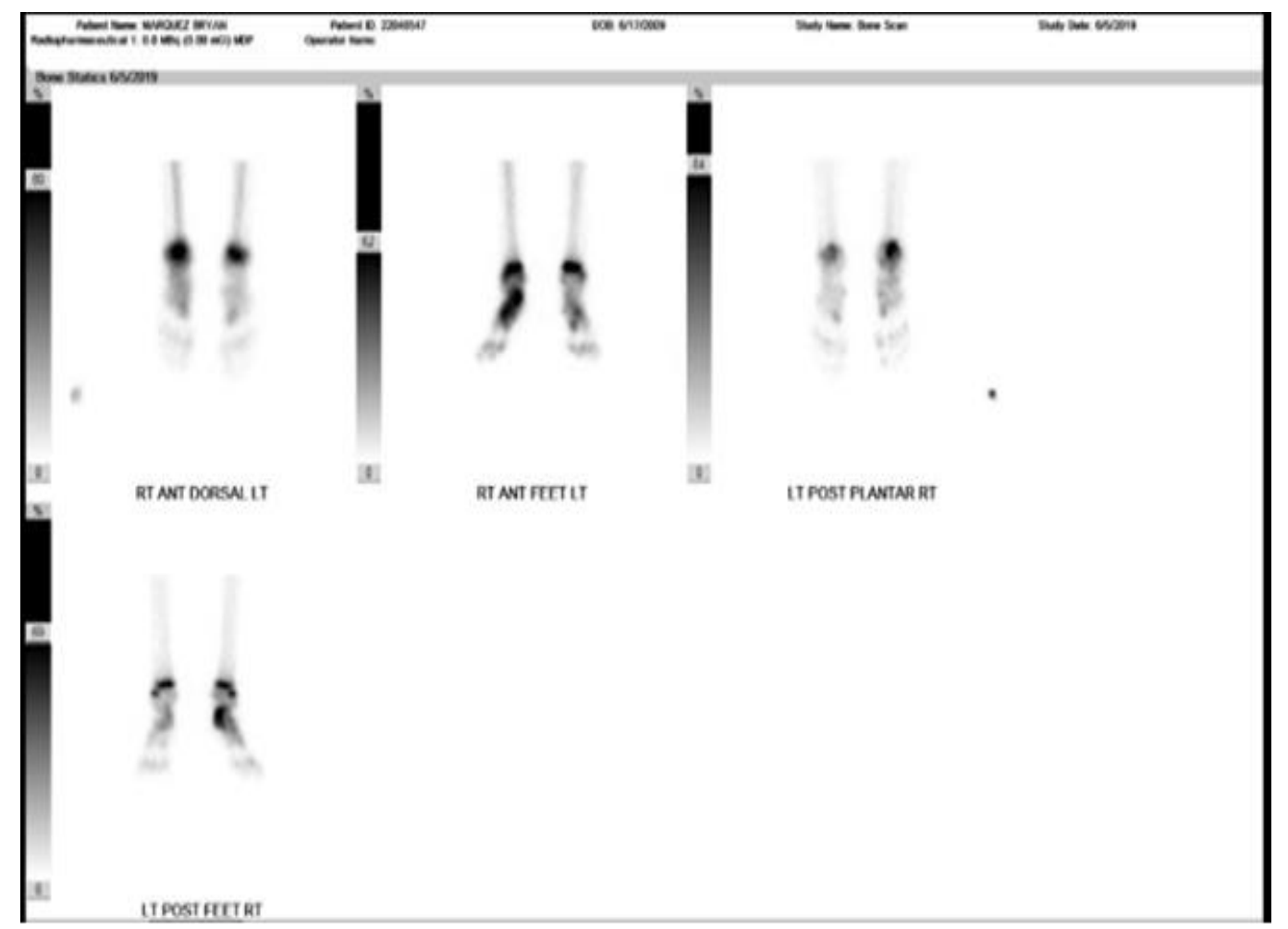

Figure 5: Bone scan with different views of the bilateral feet

The patient was started on protocol AWES1031 [Cycle 5, week 9, day 5758] for chemotherapy with Vincristine, Dexrazoxane, Doxorubicin, Cyclophosphamide, and Mesna. Eight weeks after, the patient noticed some diminishment to his mass, though it remained present and tender. With the patient's growing status and interest in playing sports, he and his parents decided it would be best to undergo a calcaneal below-the-knee amputation instead of receiving radiation therapy. The mediport was removed several weeks after. A prosthesis was placed, and the patient showed good ambulation seven months after the end of chemotherapy.

\section{Discussion}

Malignant tumors of the bone in the short bones of the distal extremities are exceedingly rare [1]. ES is the second most common primary malignant bone tumor in children, though it infrequently manifests in the bones of the feet [1,2]. ES is a tumor of neural crest origin and usually follows a reciprocal translocation, and diagnoses are made by biopsy of the bone.

In general, the tumor has a very low predilection for dissemination to regional lymph nodes, and it is not known to have skip metastases to adjacent bones [2]. In the Dahlin and Unni study covering 8,542 tumors of the bone, less than $1.2 \%$ were in the distal extremities [2]. Still, less than a fifth of these tumors were ES. The frequency of ES is less than about 1 for every 3 million per year, and of these, an exceedingly small number are found in the foot and ankle [4].

The rarity of this disease, along with its uncommon presentation in the lower extremities, has made diagnosis and standardization of care challenging [1,3]. Traditionally, chemotherapy, surgery, and radiotherapy have been used for local control of ES [2]. Optimal outcomes have been described when ES is diagnosed quickly, and devastating sequelae such as wide resections or amputations could occur without prompt recognition of the disease [2].
Cook et al. and Casadei et al. describe the pain and swelling to be the main presenting symptoms for Ewing Sarcoma, with limping/ankle sprain presentation as a rarer presentation [5-6]. In our case, the patient received an X-ray partly due to the symptom presentation's length [4 months]. However, based on the Ottawa ankle rules, an X-ray was not indicated otherwise [7]. Delayed imaging may have decreased prognosis and promoted metastasis to local/distant sites.

Casadei et al. also report that the site of the tumor and choice of treatment were the main prognostic features of the tumor [6]. They describe several patients with different treatment options from chemotherapy, below-knee amputation, and radiation therapy. Primary radiation therapy has a poor prognosis, and conservative surgical therapy [e.g., calcanectomy] is also not recommended as a calcanectomy cannot achieve adequate margins, proper reconstruction and has a higher risk of recurrence [6]. Thus, a below-the-knee amputation is recommended in these patients.

Conclusion

Ewing Sarcoma of the Calcaneus is rare, and its presentation can be mistaken for an ankle sprain. While below the knee amputation coupled with chemotherapy is the most common treatment of choice, future investigation is warranted to assess the prognosis with reconstruction procedures such as a calcanectomy.

\section{References}

1. Şahin, K., Bayram, S., \& Salduz, A. (2018). Calcaneal Ewing's Sarcoma with Skip Metastases to Tarsals and Lymph Node Involvement: A Case Report. The Journal of Foot and Ankle Surgery, 57(1), 162-166.

2. Mikel, S.-J., Julio, D., Pablo Diaz, de R., \& Luis, S. (2008). Limb Salvage in Ewing's Sarcoma of the Distal Lower Extremity. Foot \& Ankle International, 29(1), 22-28.

3. Metcalfe, J, \& Grimer, R. (2004). Ewing's sarcoma of the foot masquerading as osteomyelitis. Foot and Ankle Surgery, 10(1), 29-33. 
4. Mascard, E., Gaspar, N., Brugières, L., Glorion, C., Pannier, S., \& Gomez-Brouchet, A. (2017) Malignant tumours of the foot and ankle. EFORT Open Reviews, 2(5), 261-271.

5. Cook MA, Manfredi OL. (1996) Ewing's sarcoma of the hand: A case report. Bull Hosp Jt Dis. 55:75-77.
6. Casadei R, Magnani M, Biagini R, Mercuri M. (2004) Prognostic factors in Ewing's sarcoma of the foot. Clin Orthop Relat Res. 420:230-238.

7. Stiell I. (1996) Ottawa ankle rules. Can Fam Physician. 42:478480
This work is licensed under Creative Commons Attribution 4.0 License

To Submit Your Article Click Here: Submit Manuscript

DOI: $10.31579 / 2692-9406 / 044$
Ready to submit your research? Choose Auctores and benefit from:

* fast, convenient online submission

* rigorous peer review by experienced research in your field

* rapid publication on acceptance

* authors retain copyrights

* unique DOI for all articles

* immediate, unrestricted online access

At Auctores, research is always in progress.

Learn more www.auctoresonline.org/journals/biomedical-research-andclinical-reviews- 